\title{
Identifying Victims of Human Trafficking on International and Domestic Flights
}

\author{
Elle Gough \\ College of Liberal Arts and Sciences, University of Florida
}

Faculty mentor: Christopher McCarty, Department of Anthropology

\begin{abstract}
This research aims to determine if the current protocols on international and domestic airline carriers regarding persons traveling against their will can lead to the identification and intervention for victims $\mathrm{s}^{\mathrm{i}}$ of human trafficking. The research consists of a review of the literature on the relevant discourse relating to human trafficking, an analysis of the current human trafficking training modules readily available, in addition to a survey component, to include insight from individuals currently working in the field of airline transportation. The results of this research will lead to a more thorough understanding of how airline carriers are currently handling situations of human trafficking, and how these methods or trainings can be improved for identifying potential victims of human trafficking on flights.
\end{abstract}

\section{Introduction}

Human trafficking is a billion-dollar crime industry and a form of modern day slavery that is only growing. In February 2016, Alaska Airline's flight attendant Shelia Fedrick properly identified a situation of human trafficking on a domestic flight from Seattle to San Francisco. Fedrick was able to confirm her suspicion about the striking juxtaposition between the outward appearance of the young woman and older man flying together on the route by writing a note in the bathroom of the aircraft asking the girl if she needed help, to which she responded "yes." This instance of intervention and proper identification quickly became a national news story. Hearing the story, many individuals praised Fredrick's actions as heroic, yet wondered if her efforts could be duplicated to intervene for another victim on a flight. The goal of this research is thus to determine if the current protocols on international and domestic airline carriers regarding persons traveling against their will can lead to the identification and intervention for victims of human trafficking.

Throughout this research, human trafficking shall be defined as the "the recruitment, transportation, transfer, harboring or receipt of persons, by means of the threat or use of force or 
other forms of coercion, of abduction, of fraud, of deception, of the abuse of power or of a position of vulnerability or of the giving or receiving of payments or benefits to achieve the consent of a person having control over another person for the purposes of exploitation ${ }^{\mathrm{ii}}$," as defined by the Palermo Protocol to Prevent, Suppress and Punish Trafficking in Persons. The phrase "people traveling against their will" will also be integrated in the research, to aid in the incorporation of dialogue from flight crews that may recognize an instance of an individual traveling against their will, but do not inherently think of it as human trafficking.

This topic is of interest as there is a clear imbalance of the number of victims that have been identified, to the number of victims living worldwide. It is reported by the Polaris Project that there are 20.9 million victims of human trafficking across the globe; yet only one prominent story linking victims on planes. While the primary role of airline crews and Transportation Security Administration (TSA) members may not be to identify victims of human trafficking, it is necessary to provide training and establish protocols for this type of scenario on airline travel, as the industry becomes increasingly intercontinental. With this expanded network, it is inescapable that victims must be taking flights to reach their destinations.

\section{Methods}

For this research, the examination of protocols will come from an analysis of current training modules for airline industry personnel regarding victims of human trafficking and passengers traveling against their will. Further research will be conducted through a literature review of current work specifically pertaining to the air transportation of victims. Articles have been chosen based on their incorporation of vocabulary such as "human trafficking" and "transit."

The second aspect of this research is to summarize the data obtained by a survey of flight attendants and TSA members. The survey method allows for the airline industry employees' responses to be easily compared. The inclusion of this data allows insight into individuals' experiences with receiving training, or lack thereof. As this research pertains to the protocol for identifying victims, it was decided that the data should first be gathered from employees inside the industry rather than the victims themselves. Should this research continue further, the goal is to incorporate the voices of victims, to juxtapose what the protocol suggests versus what the victims themselves suggest for successful identification and intervention. 


\section{Results-Analysis of Human Trafficking Training Modules}

When searching for available training modules to combat human trafficking on flights, two resources are readily available. The first training source is that of Airline Ambassadors International (AAI). AAI is a non-profit organization offering online and in-person training to employees in the airline industry, teaching individuals how to spot and report cases of human trafficking. To date, the nonprofit claims to have trained 4,000 individuals in the flight industry across the United States. In their PowerPoint, AAI directs flight personnel to the Blue Lightening Initiative (BLI) created by the Department of Homeland Security (DHS). According to this protocol, if a member of flight personnel believes they have an instance of human trafficking on their flight, they should: radio the upcoming airport; provide information to the DHS Tip Line; call the National Human Trafficking Resource Center (NHTRC). AAI encourages airline personnel to be observant and note when a passenger's movement seems controlled or restricted, yet dissuades airline personnel from directly confronting any situation of human trafficking on their flights, advising instead to call authorities who can meet the plane once safely on the ground.

The second training available is through the campaign Angels at 30,000 Feet (AA30). AA30 encourages flight crew to be versed in the knowledge of human trafficking, so that it can be recognized and reported on flights. AA30 provides a training PowerPoint, as well as links to human trafficking training through entities such as the DHS.

After reviewing both entities' training slides, it is clear that AAI is focused on providing action items for instances of human trafficking, where AA30 is focused on providing basic knowledge of human trafficking. While it is not to say that there are other training modules that exist to help educate flight crews, the trainings provided by AAI and AA30 are the only two easily accessible to the public audience. If training for instances of human trafficking are going to lead to identification and intervention, there must be more comprehensive training available that provides concise steps to take when a member of a flight crew or TSA member thinks they see an instance of human trafficking.

\section{Results-Literature Review}

To fully comprehend the transportation of victims, over twenty scholarly articles with relation to "human trafficking" have been reviewed. Regretfully, most of the searches combining 
"human trafficking" and a transportation buzzword led to sparse findings. Thus the focus of this research shifted to finding scholarly articles including the phrase "victims of human trafficking."

Important to first discuss are the articles outlining the United Nations (UN) General Assembly's adoption of the Palermo Protocol in November of 2000. The purpose of this protocol is to prevent and work against trafficking in persons, especially the trafficking of women and children (Gallagher, 2002:25). According to Anne Gallagher, human trafficking can be understood as a deceptive and coercive criminal activity that manipulates individuals into exploitative situations, often luring victims through false relationships or promises of work. While the Palermo Protocol takes a step forward to hold the international community increasingly accountable for instances of human trafficking, the flaw to this protocol holds that many of the victim protection measures listed are optional for countries to adopt (Gallagher, 2002:26).

In countries such as the United States, there rests an estimation of 50,000 persons said to be trafficked each year, with individuals entering from Russia, Ukraine, Latin America, and Southeast Asia (LeRoy G. Potts, 2003:227). Roughly half of these individuals are trafficked into the United States for sweatshop labor and domestic servitude (LeRoy G. Potts, 2003:227).

Potts's research is also the first to mention the use of flights in the transportation of victims, stating that victims of human trafficking enter the United States via plane with passports belonging to the captor's relatives and family members (LeRoy G. Potts, 2003:233). This provides a sliver of insight of how victims are "hidden in plain sight" when crossing international borders.

Further research depicts that women in Thailand are given falsified passports and other documentation for their transit, which lasts anywhere between one week and one month. Women are said to be accompanied by an escort, and taught specifically how to deceive airport security members (Jones et al., 2011:206). From a victim's account, it is relayed that the women being trafficked in this kind of scenario have to study Japanese and English as a way to deceive the immigration officials when answering questions pertaining to their travels. Women are said to leave in groups of ten, as to not draw attention to the number of women crossing the border at one time. The passports and the proper monetary currencies, objects necessary for the women's transportation, are doled out days before the flights, but are taken back by the traffickers once they are successfully on the plane. (Jones et al., 2011:206). 
To directly link the critical role airlines can play in stopping the movement of human trafficking, it is noted that indicators including the number and gender of asylum seekers, the statistics of women leaving main countries of origin, and the demand for visas at main destination and transit countries can be resources to provide more accurate estimates of trafficking (Laczko \& Gramegna 2003:187). Laczko \& Gramegna also acknowledge that airlines and other transportation industries are able to collect information on their travelers, which can thus aid in the identification of victims of human trafficking (Laczko \& Gramegna, 2003:187). With the current estimates reaching millions globally, it is clear that there need to be more indicators in place to amass concrete numbers on the millions of individuals being trafficked across borders.

In Sally Engle Merry's book, The Seductions of Quantification: Measuring Human Rights, Gender Violence, and Sex Trafficking, Merry dives into the quantitative data surrounding the human trafficking industry. In her chapter, "Measuring the Unmeasurable," Merry immediately addresses why it is difficult to count victims of human trafficking: to tangibly count the number of victims is nearly impossible work due to the fact that the paths to victimhood are intricate and diverse (Merry, 2016: 113). One such entity responsible for attempting to quantify this industry is the US State Department's Trafficking in Persons (TIP) Reports. These reports are published annually by the United States government, providing estimates for the number of victims of human trafficking, along with the number of prosecutions and convictions of traffickers (Merry, 2016:113). The issue rises that individuals in the United States oftentimes struggle to be recognized as victims of human trafficking rather than as criminals. (Merry, 2016:115). This is just one instance in which the numbers reported can be skewed during data collection. As trafficking is illegal and often operates underground, victims may also be frightened to speak about their experiences, which further contributes to the unmeasurable numbers.

In further efforts to understand why there are not currently more concrete numbers on the subject, Denise Brennan discusses why vocabulary should not be limited to "victims of human trafficking." Brennan relays that people do not talk about trafficking - they talk about abuse, which skews the data pertinent solely to human trafficking (Brennan, 2005:41).

It is also pertinent here to discuss the traffickers themselves. Organized criminal groups such as those running human trafficking networks have no respect for national boundaries, which makes action all the more necessary for origin and transit countries to buckle down on 
immigration crime. (Sharron A. FitzGerald, 2012:236). Yet, as also suggested by FitzGerald, non-governmental organizations increasingly have the power to influence border and immigration control as just viewed in the analysis of training modules (Sharron FitzGerald, 2012:238). If non-governmental organizations (NGOs) can be responsible for helping train the flight industry in combating situations of human trafficking, they can also help influence airport security in using tactics to sift out potentials cases of human trafficking.

This concept of origin and destination countries is of critical value for the discussion of identifying victims. According to Benjamin Perrin, transit countries must be held as equally accountable as origin and destination counties in addressing the problem of human trafficking (Benjamin Perrin, 2010:11). Perrin remarks that transit countries provide traffickers with an advantage in routing victims to their final country of destination, as they help avoid detection from airport security members who are weary of certain countries of origin. By adding a transit country, traffickers make transportation less direct, and less suspicious (Benjamin Perrin, 2010:12).

\section{Results-Survey}

The results of the survey are based on seventeen individuals who identify as either a member of the flight crew on an international or domestic airline, or as members of TSA. The survey was distributed through Qualtrics, an online data collection and analysis website, after receiving Institutional Review Board (IRB) approval. Each individual was asked fifteen questions pertaining to their occupation, their knowledge of human trafficking, and the training they have been provided by their company. Upon reviewing the data, there were a handful of relevant statistics to be shared. It should first be noted that six different airlines are represented in the study: four domestically based airlines and two internationally based airlines. When the individuals were asked how they would define "traveling against your will?" one respondent wrote: "When you have been forced to fly by means of physical, mental, or threatened by bodily harm to your or a loved one," while another one said: "You have no say so or no way of escaping your situation, either because of a person you are traveling with or by some kind of threatening force." Later in the survey when participants were asked if their employer provides training on how to identify instances of human trafficking, $70 \%$ of respondents said yes, while nearly $18 \%$ said their employer might provide training. 


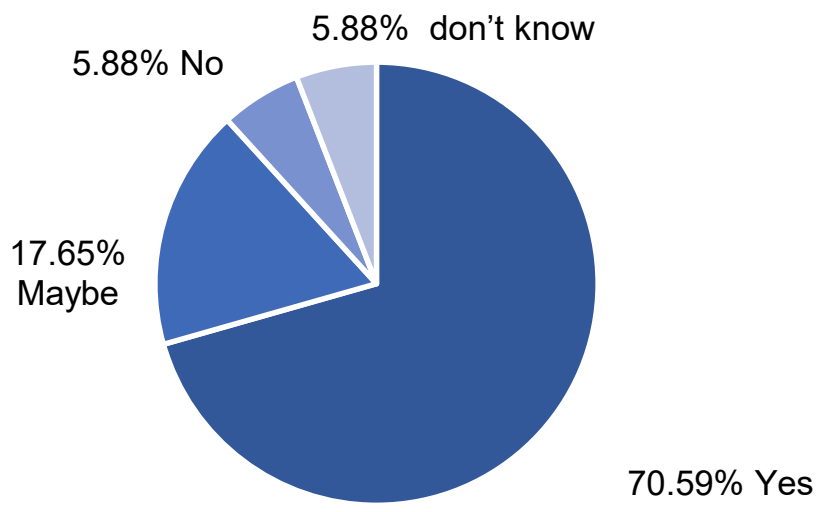

Figure 1. Does your employer provide training on how to identify instances of human trafficking?

When asked "do you have any suggestions as to how the flight industry could take a more active role in stopping human trafficking," five individuals simply stated "better training" or "more training." However, 40\% of respondents (6) who have received training said that it was only somewhat satisfactory, while $20 \%$ (3) said their training was neither satisfactory nor unsatisfactory, and 13\% (2) said it was somewhat unsatisfactory.

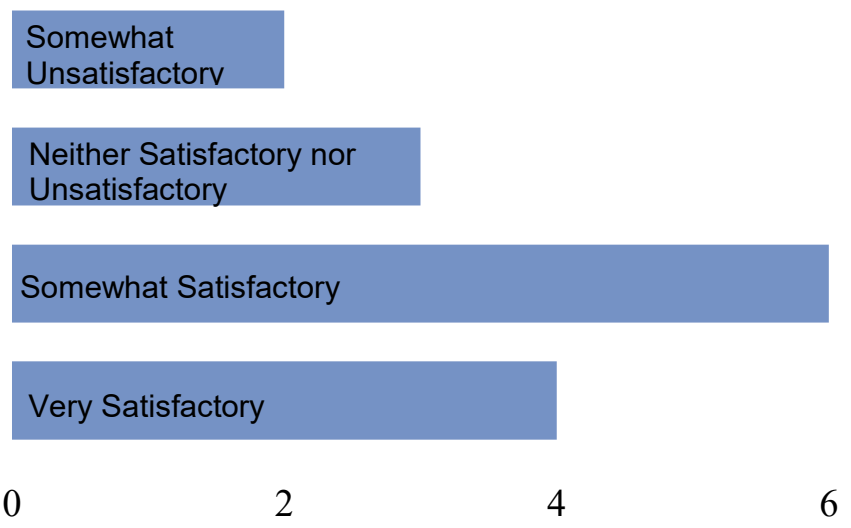

Figure 2. Satisfactory level of training to recognize and combat human trafficking

When asking about personal experiences, nearly $59 \%$ of respondents say they know an individual that has witnessed an instance of human trafficking on their flight.

\section{Yes $59 \%$} No $41 \%$

Figure 3. Has anyone you know ever witnessed an instance of human trafficking on a flight? 
While it is encouraging to see an overall higher number of individuals receiving training on human trafficking in the skies than expected, what is now concerning is the satisfactory level of such training. Finally, when asked about their airline or TSA's plan of action when they suspect that a passenger is a victim of human trafficking, six individuals reported that they would notify the captain.

One intriguing result is that one respondent answered that they had witnessed an instance of human trafficking on a flight. This individual is a flight attendant on one of the prominent domestic airline carriers in the United States, having worked in the industry for over 16 years. This individual said that they are very familiar with the subject of human trafficking, describing someone traveling against their will as "Someone traveling without wanting to go and doesn't really know the person! Being made to go against their will. Usually drugged!" The individual responded that their airline provides training on how to identify instances of human trafficking; has received said training; and finds this training to be very satisfactory. When asked which indicators they would use to assess if a passenger is a potential victim of human trafficking, this individual included: minimal baggage, lack of eye contact, inappropriate attire for their route of travel, lack of knowledge of flight itinerary, scripted communication, and specifically stated that "they are usually drugged and [you] can totally tell by [their] eyes!" This respondent said that they use the assistance of a Federal Air Marshal (FAM) to assist with the process on their international flights. This individual suggested that to better combat human trafficking in the flight industry, individuals "just [need to] be more aware about it all and always be looking for it."

While this response is the one which sheds hope that the industry is moving forward, a second respondent (a senior international flight steward who has been working for this internationally based airline for the past 1-5 years), defined trafficking as "traveling against your will" and "being forced to travel under the circumstance that you are going to be put in harm's way." Contrary to the first respondent, this respondent said that their employer does not provide training on how to identify instances of human trafficking, although they have personally received training elsewhere. While this respondent has not witnessed an instance of human trafficking, this respondent finds lack of eye contact and the lack of knowledge surrounding their itinerary as indicators for potential victims of human trafficking on a flight. When asked what their airline's plan of action is when they suspect that a passenger may be a victim of human 
trafficking, they have this to say: "As we are an internationally flying airline, it is very surprising that there are no standard procedures or plans of action in place when it comes to human trafficking. Although we have a three month training course in place to cover safety, security and service standards before being allowed to fly, our flight attendants do not receive any sort of training or information on human trafficking." When inputting suggestions as to how the flight industry could take a more active role in combating human trafficking, this respondent says: "Flight attendants go through a rigorous safety and security training program in order to be licensed to fly and prepared for any type of emergency that can occur. Human trafficking could easily be tied into the security segment of training, and I think that airlines need to learn the shocking statistics on human trafficking and realize what a huge role they can play in preventing it if their staff is trained properly to identify it."

As seen between the vast differences of these two respondents, it is evident that the entirety of the flight industry has a long way to go before all airline personnel feel as confident as the first respondent to recognize and act in situations where there is a potential victim of human trafficking. While these responses are two of the extremes in the survey, it is astonishing to find actual data that shows just how much of a lack of knowledge there still lies in addressing situations of human trafficking on flights.

\section{Discussion}

To summarize the literature reviews into one conclusion, there is very little written specifically on the aviation industry's role in human trafficking. The majority of articles reviewed only comment on the logistics of airline travel in trafficking contexts, but not on how airline personnel can combat the situation. What can be deciphered from the literature review is that women are taught to deceive airport and immigration officials, enter new countries by using forged passports, and travel on routes drawn to be as inconspicuous as possible. This provides a general knowledge on one side of the equation, but nothing on airline protocols relating to the subject.

The other overwhelmingly prevalent discourse in these articles is the problem of estimation in the human trafficking industry. With the number of trafficked persons only given in estimates, it is hard to see how fast this criminal industry is really growing. Moreover, there are many limitations placed on these estimates, as most victims of human trafficking do not self-identify as 
victims. This likely reduces the estimates of human trafficking provided in each article, making the issue more prevalent than what can currently be deduced.

From the research gathered on available human trafficking training materials, flight personnel and airport security agents are missing a vital component: the actual "what to do" portion of the discussion around trafficking. While the anti-trafficking documents viewed provide extensive information on how to identify situations of human trafficking, they do not provide concrete training on how to combat a situation of human trafficking. To better help potential victims of human trafficking, there must be more tangible protocols for flight personnel to follow when in-flight.

As evident in the survey of flight personnel, it is clear that while there may be some human trafficking training circulating the industry, there are still many individuals and airline carriers that are not providing adequate training. To talk about human trafficking does not constitute providing a tangible plan of action if the airline crew believes they see an instance of human trafficking or persons traveling against their will. Having "somewhat satisfactory" training does not constitute a level of training that should be mandatory in the flight industry.

Additionally, it is clear that this research is limited due to the lack of voices from most important population: the victims themselves. Without understanding how victims would react on flights, how are airlines supposed to build sufficient protocol for intervention? This analysis could aid in a larger, more specific framework for identifying victims of human trafficking on international and domestic flights should this project ever have the opportunity to expand.

\section{Conclusion}

The industry of human trafficking uses tactics of deception and coercion to trick victims and border officials alike when moving individuals from countries of origin, to countries of transit or destination. While preventing or combating instances of human trafficking may not be the primary concern of TSA or flight crew employees, these individuals are often the first people who can detect a situation of trafficking during transport. That means that the proper training for these individuals about how to identify and act on a situation of human trafficking could save lives.

It is apparent that the airline industry is starting to move forward in combating human trafficking, with the critique of the industry's actions being that they are slow to take effect. 
There is still a multitude of carriers that have not taken active steps to combat the situation at large. Thus it is imperative that this research brings to light the shortcomings of current literature on the transportation methods in the human trafficking industry, and the shortcomings of the current training and anti-human trafficking centered protocol on international and domestic flights. Without further research and action from airlines, there will continue to be victims of human trafficking on flights.

\section{Acknowledgements}

I would like to thank Dr. McCarty from the University of Florida's Department of Anthropology for his mentorship throughout this research project. I would also like to thank the survivors of human trafficking that I've met at Rethreaded ${ }^{\text {iii }}$ for inspiring this project.

\section{References}

Brennan, Denise. (2005). "Methodological Challenges in Research with Trafficked Persons: Tales from the Field." Article in International Migration, 43: 35-54.

FitzGerald, Sharron. (2012). "Vulnerable Bodies, Vulnerable Borders: Extraterritoriality and Human Trafficking." Article in Feminist Legal Studies, Vol. 20, no. 3: 227-244.

Gallagher, Anne. (2002). "Trafficking, smuggling and human rights: tricks and treaties.” Article in FMR 12: $25-28$.

Jones, L., Engstrom, D., Hilliard, P. and Sungakawan, D. (2011). "Human trafficking between Thailand and Japan: lessons in recruitment, transit and control." Article in International Journal of Social Welfare, 20: 203-211.

Laczko, Frank, and Marco A. Gramegna. (2003). "Developing Better Indicators of Human Trafficking." Article in The Brown Journal of World Affairs Vol. 10, no. 1: 179-94.

Merry, Sally Engle. (2016). The Seductions of Quantification: Measuring Human Rights, Gender Violence, and Sex Trafficking. The University of Chicago Press.

Perrin, Benjamin. (2010). "Just Passing Through? International Legal Obligations and Policies of Transit Countries in Combating Trafficking in Persons." Article in European Journal of Criminology, Vol. 7, no. 1:11-27.

Potts, LeRoy G. Jr. (2003). "Global Trafficking in Human Beings: Assessing the Success of the United Nations Protocol to Prevent Trafficking in Persons." Article in George Washington International Law Review, Vol. 35: 227,250. 


\section{Endnotes}

${ }^{\mathrm{i}}$ Adults induced into commercial sex through force, fraud, or coercion; children and adults induced to perform labor or services through force, fraud, or coercion (Human Trafficking Hotline).

ii Exploitation shall include, at a minimum, the exploitation of the prostitution of others or other forms of sexual exploitation, forced labor or services, slavery or practices similar to slavery, servitude or the removal of organs." -Protocol to Prevent, Suppress and Punish Trafficking in Persons, Especially Women and Children, supplementing the UN Convention against Transnational Organized Crime, Article 3(a) iii Rethreaded is a nonprofit in Jacksonville, Florida founded on providing sustainable employment for survivors of human trafficking. 